\title{
NEUROIMAGING IN PARKINSONISM
}

\section{A study with magnetic resonance and spectroscopy as tools in the differential diagnosis}

\author{
Luiz Felipe Rocha Vasconcellos', Sergio A. Pereira Novis², \\ Denise Madeira Moreira ${ }^{3,4}$, Ana Lucia Z. Rosso ${ }^{2}$, Ana Claudia C.B. Leite
}

\begin{abstract}
The differential diagnosis of Parkinsonism based on clinical features, sometimes may be difficult. Diagnostic tests in these cases might be useful, especially magnetic resonance imaging, a noninvasive exam, not as expensive as positron emission tomography, and provides a good basis for anatomical analysis. The magnetic resonance spectroscopy analyzes cerebral metabolism, yielding inconsistent results in parkinsonian disorders. We selected 40 individuals for magnetic resonance imaging and spectroscopy analysis, 12 with Parkinson's disease, 11 with progressive supranuclear palsy, 7 with multiple system atrophy (parkinsonian type), and 10 individuals without any psychiatric or neurological disorders (controls). Clinical scales included Hoenh and Yahr, unified Parkinson's disease rating scale and mini mental status examination. The results showed that patients with Parkinson's disease and controls presented the same aspects on neuroimaging, with few or absence of abnormalities, and supranuclear progressive palsy and multiple system atrophy showed abnormalities, some of which statistically significant. Thus, magnetic resonance imaging and spectroscopy could be useful as a tool in differential diagnosis of Parkinsonism.
\end{abstract}

KEY WORDS: Parkinson's disease, progressive supranuclear palsy, multiple system atrophy, magnetic resonance, spectroscopy.

\section{Neuroimagem no parkinsonismo: estudo com ressonância magnética e espectroscopia por ressonância como ferramentas no diagnóstico diferencial}

Resumo - O diagnóstico diferencial do parkinsonismo baseado em parâmetros clínicos pode ser difícil. Alguns exames complementares podem ser úteis, especialmente a ressonância magnética, um método não invasivo, de menor custo quando comparado a tomografia por emissão de pósitrons, proporcionando uma análise anatômica satisfatória. A ressonância por espectroscopia analisa o metabolismo cerebral, com resultados variáveis na literatura no estudo das sindromes parkinsonianas. Selecionamos 40 indivíduos para realização de ressonância magnética e espectroscopia, sendo 12 com doença de Parkinson, 11 com paralisia supranuclear progressiva, 7 com atrofia de múltiplos sistemas tipo parkinsoniana e 10 indivíduos sem manifestações neurológicas ou psiquiátricas (grupo controle). As escalas clínicas analisadas foram a de Hoenh e Yahr, unified Parkinson's disease rating scale e o mini-exame do estado mental. Os resultados encontrados revelaram que pacientes com doença de Parkinson e controle apresentavam em geral o mesmo aspecto por imagem enquanto os grupos paralisia supranuclear progressiva e atrofia de múltiplos sistemas com anormalidades, havendo significância estatística em algumas variáveis. A ressonância magnética e a espectroscopia podem ser úteis no diagnóstico diferencial do parkinsonismo.

PALAVRAS-CHAVE: Parkinsonismo, doença de Parkinson, paralisia supranuclear progressiva, atrofia de múltiplos sistemas, ressonância magnética, espectroscopia.

\footnotetext{
Universidade Federal do Rio de Janeiro, Hospital Universitário Clementino Fraga Filho and Instituto de Neurologia Deolindo Couto and Hospital PróCardíaco: 'Hospital dos Servidores do Estado, Rio de Janeiro RJ, Brazil; ${ }^{2} \mathrm{Hospital}$ Universitário Clementino Fraga Filho and ${ }^{3}$ Instituto de Neurologia Deolindo Couto, Universidade Federal do Rio de Janeiro, Rio de Janeiro RJ, Brazil; ${ }^{4}$ Hospital Pró-Cardíaco, Serviço de Radiologia, Rio de Janeiro RJ, Brazil; ${ }^{5}$ Fundação Oswaldo Cruz, Rio de Janeiro RJ, Brazil.
}

Received 14 July 2008, received in final form 16 October 2008. Accepted 25 November 2008.

Dr. Luiz Felipe Rocha Vasconcellos - Rua Conde de Bonfim 211/702 - 22411-001 Rio de Janeiro RJ - Brasil. E-mail: luizneurol@terra.com.br 
The Parkinsonian syndrome or parkinsonism (PK) correspond to clinical signs of rigidity, bradykinesia, tremor, and postural instability, and the presence of two of them is required to define probable $\mathrm{PK}$, and one of these two signs must be tremor or rigidity. The PK is classified as primary, secondary, atypical or plus, and hereditary ${ }^{1,2}$. The accurate diagnosis may be difficult based upon clinical signs, especially at early stages, and in some cases only after the performance of neuropathological studies it could be possible to define the diagnosis ${ }^{3-7}$. It is important to determine this due to the different prognosis, pharmacotherapy, and epidemiological analysis ${ }^{8,9}$.

Magnetic resonance imaging (MRI) and spectroscopy by MRI (MRS) are noninvasive tools helping the physician to establish a more accurate diagnosis. MRI offers an adequate analysis of abnormalities in the basal nuclei, midbrain, pons, medulla, and cerebellum, which are impaired in atypical $\mathrm{PK}^{10-23}$.

We selected patients with diagnosis of PK and analyzed the usefulness of neuroimaging (MRI and MRS) in the differential diagnosis of this condition.

\section{METHOD}

We designed a prospective, case-control, double-blind, 24 months study. The MRI was performed in a GE machine, $1.5 \mathrm{Te}$ sla Sigma Horizon model, the sequences analyzed were T 1, T 2, flair, diffusion, axial-oblique in T 2 in Fast Spin-Echo (FSE) and Proton Density (PD) and T 2 in Spin-Echo (SE). In addition to 5 $\mathrm{mm}$ slices, we included $3 \mathrm{~mm}$ slices in the lentiform nucleus. The MRS was single voxel (8 cc), PRESS technique (TR/TE=1500/50) bilaterally in lentiform nucleus, midbrain, white matter of frontal lobe and hippocampus.

Informed consent was obtained from all patients or their immediate relatives, and the study was approved by the Ethics Committee of the institutions involved.

Forty individuals were included in this study (age range: 50 to 85 years), 30 with Parkinsonian syndrome and 10 without any neurological or psychiatric disorders. Four patients were exclud- ed, two due to cerebrovascular disease showed in MRI, and two related to technical problems during MRI.

All individuals were examined by the same neurologist, and 26 patients met the criteria for probable Parkinson's disease (PD) [ $n=10]$, (Gelb et al. ${ }^{24}$ ), progressive supranuclear palsy (PSP) [n=10], (Tolosa et al. ${ }^{25}$ ), and multiple system atrophy-parkinsonian type (MSA-P) [n=6], (Gilman et al. ${ }^{26}$ ). For clinical assessment, the scales adopted were Hoehn-Yahr stage ${ }^{27}$, unified Parkinson's disease rating scale (UPDRS) Part $\mathrm{III}^{28}$ and mini-mental status examination $\left(\right.$ MMSE) ${ }^{29}$. The patients performed the Tilt Table test for evaluation of dysautonomia.

The indication for MRI was the same for all individuals: "parkinsonism", so that the radiologist did not know the actual diagnosis.

The variables in MRI were: anteroposterior diameter of the medulla, pons, midbrain and fourth ventricle, transverse diameter of lateral and third ventricles, presence of cerebral and/or cerebellar atrophy, and signal abnormalities in white matter, lentiform, midbrain, pons and medulla, linear posterolateral hypersignal in lentiform nucleus, and transverse signal in the pons.

MRS was performed bilaterally on white matter of frontal lobe, lentiform nucleus, midbrain and hippocampus. We used the $\mathrm{N}$-acetyl aspartate/creatine (NAA/Cr) and N-acetyl aspartate/choline (NAA/Cho) relation. The value adopted was the mean of both white matter from the frontal lobe and the hippocampus, and the contralateral relation of the most affected side on the lentiform and midbrain, and when there was symmetry, the mean was obtained.

\section{Statistical analysis}

For quantitative variables the statistical analysis adopted was Student's t-test or the Mann-Whitney test, and for qualitative the X2, Fisher and Mantel Haenszel. There was statistical significance when $\mathrm{p}$ value was $<0.05$.

\section{RESULTS}

The clinical variables that did not show differences statistically significant among the three groups were: age, disease duration, and sex (Table 1).

Table 1. Demographic and clinical characteristics by patient group.

\begin{tabular}{lcccc}
\hline Characteristics & PD & MSA-P & PSP & Control subjects \\
\hline $\mathrm{N}$ & 10 & 6 & 10 & 10 \\
Age $(\mathrm{yr})$ & $64 \pm 10.4$ & $73.3 \pm 13.2$ & $70.3 \pm 7.2$ & $63.4 \pm 10.3$ \\
Disease duration $(\mathrm{yr})$ & $8.5 \pm 3.5$ & $8 \pm 2$ & $6.6 \pm 3.1$ & $\mathrm{NA}$ \\
Number of men & 6 & 4 & 5 & 6 \\
MMSE & 26 & 24 & 20 & 30 \\
Hoehn and Yahr stage & 3 & 5 & 4 & $\mathrm{NA}$ \\
UPDRS - Part III & 21 & 49 & 33 & $\mathrm{NA}$
\end{tabular}

Mean values \pm Standard Deviation (SD) are given for age and disease duration; Mean values are given for MMSE, Hoehn-Yahr stage and UPDRS; PD, Parkinson disease; MSA-P, multiple system atrophy; PSP, progressive supranuclear palsy; NA, not applicable. 

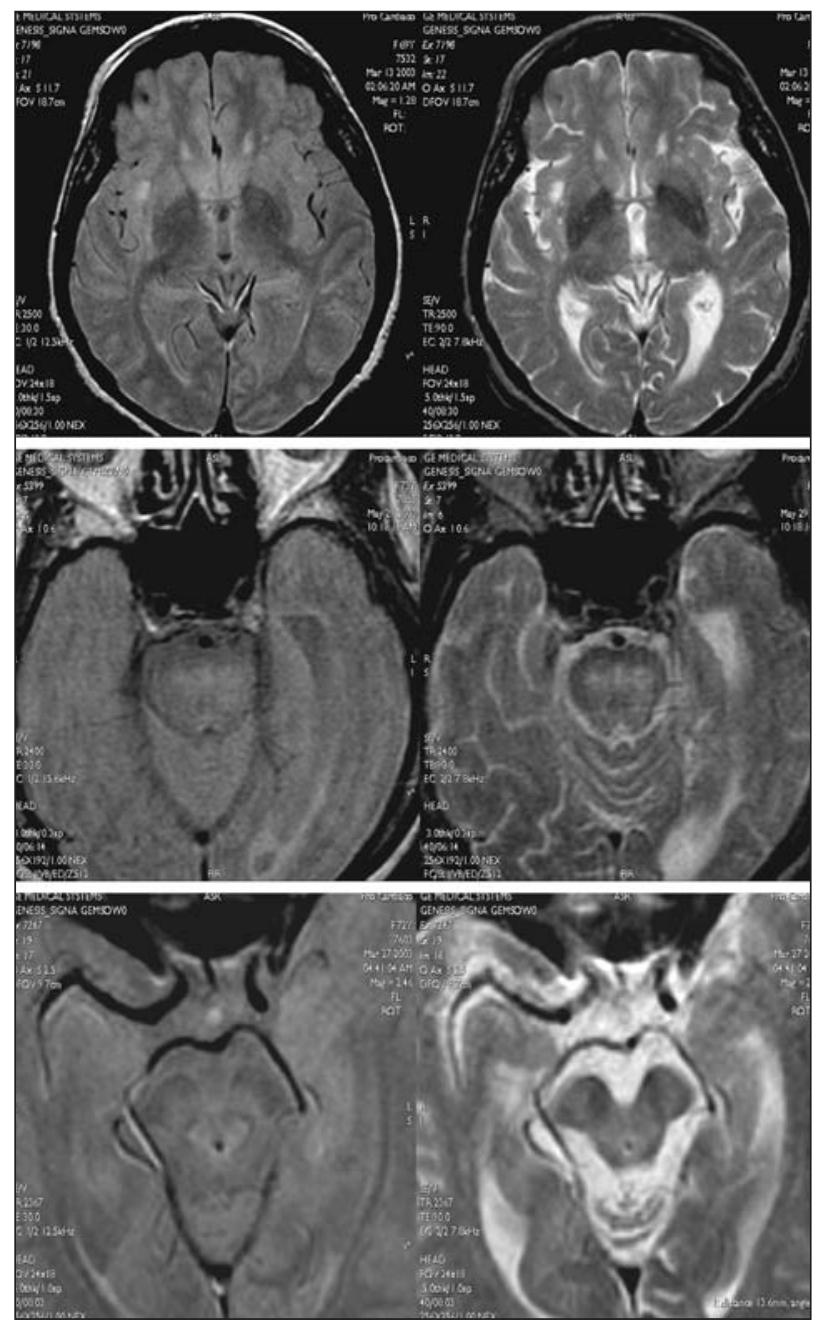

Fig 1. Hyposignal in the lentiform nucleus (found in $67 \%$ of MSA-P group), and hypersignal in the pons (found in $33 \%$ of MSA-P group) and the midbrain on T2, flair or DP sequences (found in $70 \%$ of PSP group).

Dysautonomia was documented in $20 \%$ of PD and $100 \%$ of MSA-P.

In the motor scales (UPDRS and Hoehn and Yahr), the results showed higher scores in PSP and MSA-P than in PD. There was statistical significance in PD versus MSA-P (Hoe-

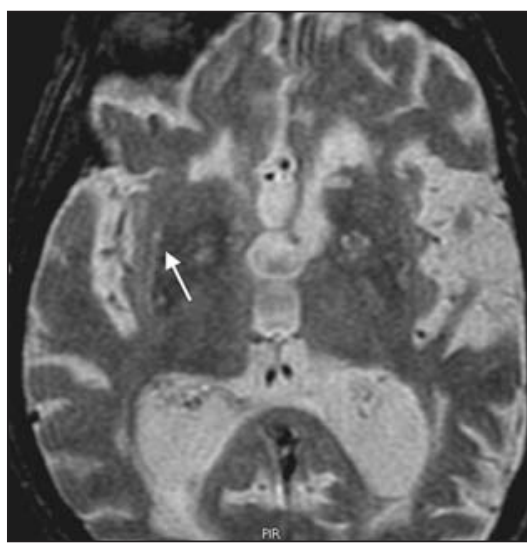

Fig 2. Posterolateral linear hypersignal in the lentiform nucleus, with asymmetric symptoms, T2 sequence (found in 50\% in MSA-P group).

hn Yahr $p=0.021$ and UPDRS $p=0.029$ ), and a trend to statistical significance in PD and PSP (Hoehn and Yahr, and UPDRS $\mathrm{p}=0.08$ ).

Patients with PSP presented lower scores in MMSE, followed by MSA-P and PD, and there was statistical significance in the three groups comparing to controls (PD $p=0.046$; MSA-P $p=0.002$, and PSP $p=0.0004$ ) (Table 1).

Image variables demonstrated cerebral atrophy in all cases of PSP and MSA-P, having statistical significance in PD versus PSP $(p=0.001)$, $P D$ versus MSA-P $(p=0.006)$, controls versus PSP $(p=0.011)$, and controls versus MSA-P (0.043). Cerebellar atrophy was more common in MSA-P and PSP, with statistical significance in PD versus MSA-P $(p=0.043)$, controls versus PSP $(p=0.034)$ and controls versus MSA-P ( $p=0.010)$. We observed a higher prevalence of white matter alterations in atypical PK with no statistical significance. Signal change in the lentiform nucleus was observed more commonly in MSA-P and PSP, but no statistical significance was documented (Figs 1-3).

The posterolinear increased signal in the lentiform nucleus was demonstrated only in the MSA-P and PSP groups, presenting statistical significance when compar-

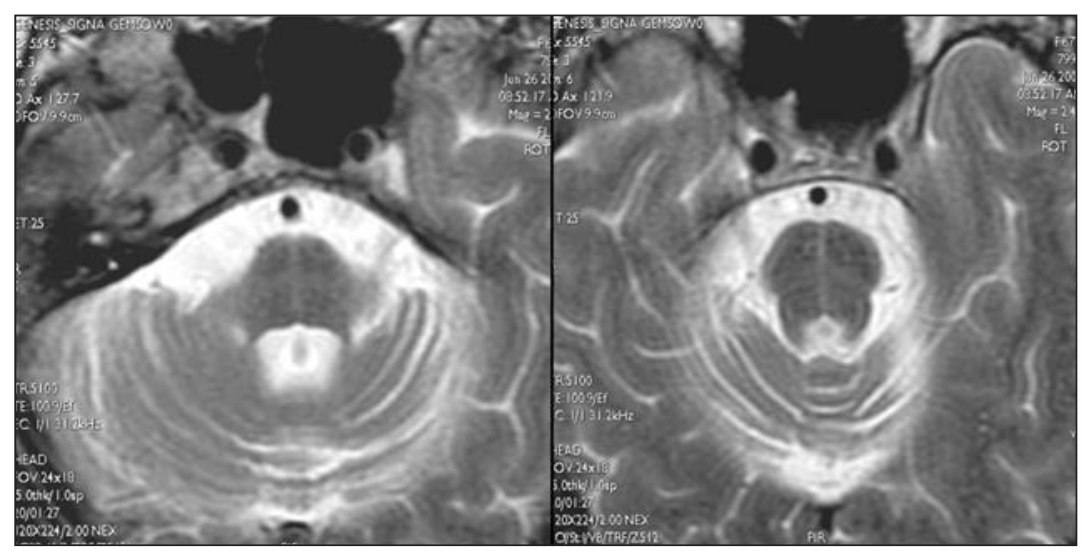

Fig 3. Transverse signal ("hot cross bun sign") in the pons, $T 2$ sequence (found in $33 \%$ of MAS-P group). 
Table 2. Magnetic resonance variables (quantitative).

\begin{tabular}{lcccc}
\hline & \multicolumn{4}{c}{ Mean values (mm) \pm SD } \\
\cline { 2 - 5 } & PD & MSA-P & PSP & Control subjects \\
\hline Posteroanterior diameter of the midbrain & $17 \pm 1.06$ & $15 \pm 1.54$ & $14 \pm 2.32$ & $17 \pm 1.32$ \\
Posteroanterior diameter of the pons & $22 \pm 2.22$ & $20 \pm 2.51$ & $19 \pm 1.75$ & $23 \pm 1.71$ \\
Posteroanterior diameter of the medulla & $13 \pm 1.81$ & $12 \pm 1.23$ & $12 \pm 1.7$ & $14 \pm 1.17$ \\
Transverse diameter of the lateral ventricles & $32 \pm 7.47$ & $37 \pm 7.6$ & $39 \pm 5.7$ & $33 \pm 4.85$ \\
Transverse diameter of the third ventricle & $3 \pm 3.71$ & $5 \pm 3.24$ & $8 \pm 2.21$ & $4 \pm 3.38$ \\
Posteroanterior diameter of the fourth ventricle & $9 \pm 0.93$ & $10 \pm 1.59$ & $10 \pm 2.29$ & $9 \pm 1.82$ \\
\hline
\end{tabular}

PD, Parkinson disease; MSA-P, multiple system atrophy; PSP, progressive supranuclear palsy.

Table 3. Spectroscopy variables.

\begin{tabular}{lccccc}
\hline Variables & & PD & PSP & MSA & Control subjects \\
& & $(\mathrm{N}=10)$ & $(\mathrm{N}=10)$ & $(\mathrm{N}=6)$ & $1.45)$ \\
\hline NAA/Cr lentiform nucleus & Mean & 1.46 & 1.31 & 1.4 & 1.74 \\
NAA/Cr midbrain & Mean & 1.77 & 1.5 & 1.53 & 1.65 \\
NAA/Cr frontal lobe & Mean & 1.51 & 1.47 & 1.33 & 1.56 \\
NAA/Cr Hippocampus & Mean & 1.36 & 1.2 & 1.55 & 1.42 \\
NAA/Chol lentiform nucleus & Mean & 1.64 & 1.43 & 1.69 & 1.56 \\
NAA/Chol midbrains & Mean & 1.53 & 1.34 & 1.55 & 1.56 \\
NAA/Chol frontal lobe & Mean & 1.71 & 1.57 & 1.42 & 1.62 \\
NAA/Chol Hippocampus & Mean & 1.4 & 1.41 & 1.5
\end{tabular}

Naa, N-Acetyl aspartate; $\mathrm{Cr}$, creatine; Col, choline; $\mathrm{Naa} / \mathrm{Cr}$ in the lentiform nucleus, PD versus PSP controls $(\mathrm{p}=0.049)$ and PSP versus controls ( $\mathrm{p}=0.036)$; $\mathrm{Naa} / \mathrm{Cr}$ in the hippocampus, PSP versus control ( $p=0.0007$ ); Naa/Col in the midbrain, PSP versus MSA ( $p=0.028)$ and PSP versus control ( $p=0.046$ ).

ing PD versus MSA-P $(\mathrm{p}=0.03)$, and controls versus MSA-P $(p=0.03)$.

Signal changes in the midbrain were more commonly observed in PSP, and in MSA-P in the pons, with statistical significance in midbrain $(\mathrm{p}=0.0015)$.

The quantitative variables detailed in Table 2 demonstrated that some measurement of brainstem and ventricular system had statistical significance to differentiate atypical PK and PD/control group. The measurements that revealed statistic significance according to region and groups were:

Midbrain - PD versus PSP ( $P=0.002)$, PD versus MSA-P $(p=0.012)$, controls versus PSP $(p=0.002)$ and controls versus MSA-P (0.010).

Pons - DP versus PSP $(p=0.012)$, PSP versus controls $(p=0.007)$ and MSA-P versus controls $(p=0.01)$.

Medulla - DP versus MSA-P ( $p=0.041)$, PSP versus controls $(p=0.008)$ and MSA-P versus controls $(p=0.001)$.

Lateral ventricles $-P D$ versus PSP $(p=0.041)$ and controls versus $\mathrm{PSP}(\mathrm{p}=0.045)$.

Third ventricle $-D P$ versus PSP $(p=0.015)$ and PSP versus controls $(p=0.009)$.

Fourth ventricle - DP versus PSP $(p=0.037)$ and DP versus MSA-P $(p=0.024)$.
The values of MRS are related in Table 3 and some reduction showed statistical significance:

NAA/Cr in the lentiform nucleus - PD versus PSP ( $p=0.049)$ and PSP versus controls $(p=0.036)$.

$\mathrm{NAA} / \mathrm{C}$ in the hippocampus - PSP versus control $(\mathrm{p}=0.0007)$.

$\mathrm{NAA} / \mathrm{Cho}$ in the midbrain $-\mathrm{PSP}$ versus MSA $(\mathrm{p}=0.028)$ and PSP versus control $(\mathrm{p}=0.046)$.

\section{DISCUSSION}

The increase of life expectancy results in a raise of degenerative disorders. PD is one of the most common neurodegenerative disease (followed by Alzheimer disease), as epidemiological studies show in the literature ${ }^{30}$. Parkinsonian signs may be seen in different medical conditions, having variable course, treatment and prognosis so it is important to determine an accurate diagnosis as soon as possible ${ }^{8,9}$. Based only in clinical data, especially in the early stages of the disease, physicians may not establish a correct diagnosis ${ }^{3-7}$.

The accuracy of clinical diagnosis of PK is variable, in PD ranging from $76 \%$ to $90 \%$, and in others PK the accuracy is even lower ${ }^{3-7}$. One study conducted in a movement disorders specialized center, showed that the positive predic- 
tive value of PD was $98.6 \%$, and to atypical parkinsonism $71.4 \%$, confirming that the diagnosis of atypical PK, even in specialized centers, is sometimes difficult to establish ${ }^{7}$.

Some diagnostic tests could be useful for the differential diagnosis of PK, and MRI is one of the most impor$\operatorname{tant}{ }^{10-23}$. Our objective was to determine the usefulness of MRI and MRS in a PK group, based on well known imaging aspects according to the subtype of PK, assessing which variables had statistic significance in these groups.

We included the three PK that most frequently lead to misdiagnosis: PD, MSA-P, and PSP, all compared to control group. The criteria used to clinical diagnosis was the most specific, as showed in the literature ${ }^{24-26}$.

We used three clinical scales: motor part of UPDRS, Hoehn and Yahr and MMSE ${ }^{27-29}$. These scales showed increased motor impairment (higher scores in UPDRS and Hoehn-Yahr) in the MSA-P, followed by PSP, and increased cognitive impairment (lower scores of MMSE) in PSP, followed by MSA-P. We did not observe a correlation between the duration of the symptoms with MRS abnormalities, but with the clinical diagnosis of patient.

MRI variables demonstrated that some are helpful to differentiated PK syndromes, as the presence of cerebral and cerebellar atrophy and signal enhancement of some encephalic structures (lentiform nucleus, midbrain and pons), more common in atypical PK.

The decreased signal enhancement in the lentiform nucleus may be observed in normal aging, so in our study we only considered it as "abnormal" if the hypointensity was moderate to severe ${ }^{15,31}$. Our data showed that moderate to severe decrease hypointensity in lentiform nucleus was observed more frequently in MSA and PSP, with no difference between PD and control groups and when it was associated with posterolateral linear hypersignal in putamen, suggested the diagnosis of atypical PK (more frequently in MSA group).

The most useful measurement of encephalic diameter in our study was the midbrain, as it had been shown by Warmutth et al. ${ }^{18}$. Values below $15 \mathrm{~mm}$ in the midbrain suggested PSP or MSA-P, with lower values seen in PSP.

Some values of MRS had statistical significance, the most useful were from the lentiform nucleus, hippocampus, and midbrain, depending on the diagnosis, indicating a severe neuronal impairment (neuronal death). There are few studies in which the brainstem is evaluated by MRS, due to technical difficulties (bone proximity). In our study we demonstrated that it is feasible, but we had to repeat the exam, in some cases several times, to achieve a consistent chart. The study done by Watanabe et al. ${ }^{23} \mathrm{dem}-$ onstrated the usefulness of MRS of the pons in MSA pa- tients. As the midbrain is the most affected area in PSP, we analyzed it by MRS. We have found NAA/Cho decrease in midbrain of PSP group with statistical significance, indicating neuronal loss.

Based on our data we concluded that: (1) Patients with PSP and MSA-P presented increased motor and cognitive impairment in the scales used, correlating with decrease in NAA/Cr in lentiform nucleus and NAA/Cho in midbrain in the PSP group; (2) Cerebral and cerebellar atrophy were more prevalent and severe in PSP and MSA-P groups; (3) Linear hypersignal in the lateral portion of the putamen, hypersignal in midbrain and in pons, all suggest the diagnosis of PSP or MSA-P; (4) Midbrain or pons atrophy suggests atypical parkinsonism, the former PSP, and the latter MSA-P; (5) Comparing the two methods, MRI and MRS, the former had better applicability.

Our study showed that anatomical analysis through MRI and MRS of some areas could be useful in the differential diagnosis of PD and atypical PK, helping physicians to establish a more accurate diagnosis of PK.

\section{REFERENCES}

1. Shannon KM. Movement disorders. In: Bradley WG, Daroff RB, Fenichel GM, Jankovic J (Eds). Neurology in clinical practice. $4^{\text {th }}$ ed. Philadelphia: Butterworth and Heinemann 2004:2125-2168.

2. Fahn S, Przedborski S. Distúrbios do movimento. In: Rowland LP (Ed) Tratado de neurologia - Merritt's. 10ª ed. Tradução: Araújo CLC, Mundim FD. Revisão técnica: Cavalcanti JLS. Rio de Janeiro: Guanabara Koogan 2000:589-604

3. Rajput AH, Rozdilsky B, Rajput A. Accuracy of clinical diagnosis in parkinsonism: a prospective study. Can J Neurol Sci 1991;18:275-278.

4. Hughes AJ, Daniel SE, Kilford L, Lees AJ. Accuracy of clinical diagnosis of idiopathic Parkinson's disease: a clinico-pathological study of 100 cases. J Neurol Neurosurg Psychiatry 1992;55:181-184.

5. Jankovic J, Rajput AH, McDermott MP, Perl DP. The evolution of diag nosis in early Parkinson disease. Parkinson Study Group. Arch Neurol 2000;57:369-372.

6. Carrilho PE, Barbosa ER. Progressive supranuclear palsy in a sample of Brazilian population: clinical features of 16 patients. Arq Neuropsiquiatr 2002;60:917-922.

7. Hughes AJ, Daniel SE, Ben-Shlomo Y, Lees AJ. The accuracy of diagnosis of parkinsonian syndromes in a specialist movement disorder service. Brain 2002;125:861-870.

8. Tison F, Yekhlef F, Chrysostome V, et al. Parkinsonism in multiple system atrophy: natural history, severity (UPDRS-III), and disability assessment compared with Parkinson's disease. Mov Disord 2002;17:701-709.

9. Watanabe H, Saito Y, Terao S, et al. Progression and prognosis in multiple system atrophy: an analysis of 230 Japanese patients. Brain 2002;125: 1070-1083.

10. Bhattacharya K, Saadia D, Eisenkraft B, et al. Brain magnetic resonance imaging in multiple-system atrophy and Parkinson disease: a diagnostic algorithm. Arch Neurol 2002;59:835-842.

11. Warmuth-Metz M, Naumann M, Csoti I, Solymosi L. Measurement of the midbrain diameter on routine magnetic resonance imaging: a simple and accurate method of differentiating between Parkinson disease and progressive supranuclear palsy. Arch Neurol 2001;58:1076-1079.

12. Righini A, Antonini A, Ferrarini M, et al. Thin section MR study of the basal ganglia in the differential diagnosis between striatonigral degeneration and Parkinson disease. J Comput Assist Tomogr 2002;26:266-271.

13. Schocke MF, Seppi K, Esterhammer R, et al. Diffusion-weighted MRI differentiates the Parkinson variant of multiple system atrophy from PD. Neurology 2002;58:575-580.

14. Seppi K, Schocke MF, Esterhammer R, et al. Diffusion-weighted imag ing discriminates progressive supranuclear palsy from PD, but not from the parkinson variant of multiple system atrophy. Neurology 2003;60: 922-927. 
15. Kraft E, Trenkwalder C, Auer DP. T2*-weighted MRI differentiates multiple system atrophy from Parkinson's disease. Neurology 2002;59: 1265-1267.

16. Hutchinson M, Raff U. Structural changes of the substantia nigra in Parkinson's disease as revealed by MR imaging. Am J Neuroradiol 2000;21: 697-701.

17. Schrag A, Good CD, Miszkiel K, et al. Differentiation of atypical parkinsonian syndromes with routine MRI. Neurology 2000;54:697-702.

18. Asato R, Akiguchi I, Masunaga S, Hashimoto N. Magnetic resonance imaging distinguishes progressive supranuclear palsy from multiple system atrophy. J Neural Transm 2000;107:1427-1436.

19. Vymazal J, Righini A, Brooks RA, et al. T1 and T2 in the brain of healthy subjects, patients with Parkinson disease, and patients with multiple system atrophy: relation to iron content. Radiology 1999;211:489-495.

20. Tedeschi G, Litvan I, Bonavita S, et al. Proton magnetic resonance spectroscopic imaging in progressive supranuclear palsy, Parkinson's disease and corticobasal degeneration. Brain 1997;120:1541-1552.

21. Abe K, Terakawa H, Takanashi M, et al. Proton magnetic resonance spectroscopy of patients with parkinsonism. Brain Res Bull 2000;52: 589-595.

22. Federico F, Simone IL, Lucivero V, et al. Usefulness of proton magnetic resonance spectroscopy in differentiating parkinsonian syndromes. Ital J Neurol Sci 1999;20:223-239.
23. Watanabe H, Fukatsu H, Katsuno M, et al. Multiple regional 1H-MR spectroscopy in multiple system atrophy: NAA/Cr reduction in pontine base as a valuable diagnostic marker. J Neurol Neurosurg Psychiatry 2004;75:103-109.

24. Gelb DJ, Oliver E, Gilman S. Diagnostic criteria for Parkinson disease. Arch Neurol 1999;56:33-39.

25. Tolosa E, Valldeoriola F, Marti MJ. Clinical diagnosis and diagnostic criteria of progressive supranuclear palsy (Steele-Richardson-Olszewski syndrome). J Neural Transm 1994;42(Suppl):S15-S31.

26. Gilman S, Low PA, Quinn N, et al. Consensus statement on the diagnosis of multiple system atrophy. J Neurol Sci 1999;163:94-98.

27. Hoehn MM, Yahr MD. Parkinsonism: onset, progression and mortality. Neurology 1967;17:427-442.

28. We Move. Disponível em < http: / / www.wemove.org. Acesso em: 17, maio de 2002.

29. Brucki SMD, Nitrini R, Caramelli P, Bertolucci PHF, Okamoto IH. Sugestões para o uso do mini-exame do estado mental no Brasil. Arq Neuropsiquiatr 2003;61:777-782.

30. Prusiner SB. Shattuck lecture-neurodegenerative diseases and prions. N Engl J Med 2001;344:1516-1526.

31. Drayer BP. Imaging of the aging brain: Part I. Normal findings. Radiology 1988;166:785-796. 